\title{
Shape memory alloy actuators for active disassembly using 'smart' materials of consumer electronic products
}

\author{
J. D. Chiodo, N. Jones, E. H. Billett and D. J. Harrison \\ Cleaner Electronics Research, Brunel University, Runnymede Campus, Egham, Surrey, TW20
}

\begin{abstract}
This paper reports the preliminary to current development of Shape Memory Alloy (SMA) actuators within their application in 'Active Disassembly using Smart Materials' (ADSM). This non-destructive self-dismantling process is to aid recycling of consumer electronic products. Actuators were placed in single and multi-stage hierarchical temperature regimes after being embedded into macro and sub-assemblies of electronic product assemblies. Findings include active disassembly and a hierarchical dismantling regime for product dismantling using developed SMA actuators embedded into candidate products.
\end{abstract}

Author Keywords: Alloy actuators; ADSM; Electronic products

\section{Introduction}

Active Disassembly using Smart Materials (ADSM) was tested in a number of different test regimes. Earlier experiments consisted of simply testing the concept on one time disassembly per product tests. Later experiments consisted of tests on more than one type of product with various Shape Memory Alloy (SMA) actuators in the same dismantling facility in a hierarchical temperature regime.

With SMA actuators inside the candidate products, the products would enter a sequence of controlled temperature changes in which the SMA devices would be activated at appropriate austenite finishing $\left(A_{f}\right)$ stages. ADSM would then occur allowing different components to be sorted after, through conventional mechanical sorting technologies. This would be possible using products designed for 'Active Disassembly using Smart Materials' ([1]). ADSM could also provide an increase in the range of recyclable products as a larger variety of consumer products 
manufactured by various consumer electronics manufacturers could be recycled at the same facility ( [2] $]$ ).

ADSM was applied in single disassembly procedures on a variety of small consumer electronic products. Work also includes multi-stage generic disassembly through a temperature hierarchy (70, 85,100 and $120^{\circ} \mathrm{C}$ ) on product macro and sub-assemblies with a variety of force provisions available from a number of NiTi and CuZnAl SMA actuators. Design for the inclusion of ADSM requires changes to the product's internal design features. General methodology in design modifications for the inclusion of smart material or ADSM devices in products is described. Final work includes EoL comparison strategies of ADSM with conventional practice observing how they would offer a way forward in mind of future legislation considerations.

\section{Background}

Currently, robotic disassembly is cost prohibitive. Hand disassembly is only economic for a small proportion of the input material [3] . The ADSM approach to recyclability and reuse of constituent components would widen the narrow band of economically feasible recyclable products. Future trends in product design engineering point towards recycling as an integral part of the life cycle of electronic consumer products. Automation of dismantling the post consumer product is still seen as a product-specific endeavour. As the number of electronic products increases dramatically, current models of production and 'unproduction' seems outdated. This system would also enable manufacturers to separate toxic and dissimilar components and allow their reuse or safer disposal. This work, while focussed on electronic products, has the potential to lead to more generic applications in a wide range of industries such as white and brown goods.

Results of the application of SMA devices in the ADSM of assembled products are reported. The smart materials considered in this study are alloys of nickel-titanium (NiTi) and copper-zincaluminum (CuZnAl). The range of permissible ambient temperatures, basic design and the actuator transformation temperatures ([4] $)\left(A_{f}\right)$ is considered. The designs of the actuators employed in these product trials are not optimal.

Work concentrated on the use of SMA and other smart material releasable fasteners and actuators on modem mobile phones, portable CD players, cassette players, play stations, calculators, computers and peripherals, and various stereo equipment, etc. The overall purpose of the work is to provide a mechanism to help reduce environmental impact by encouraging manufactures to 
adopt generic dismantling as a possible driver for a lower cost per unit recycling system. This is largely due to the elimination of robots and hand dismantling where the majority of the dismantling cost is apparent.

The work has been funded in the UK by the Engineering and Physical Research Council (EPSRC). The work started in a 1-year project in 1996; looking at the preliminary investigation of using SMART materials such as Shape Memory Alloys and Shape Memory Polymer in the design of actuators and releasable fasteners to be used in modem products. In 1998 a subsequent 2-year project began investigating a more in-depth study called 'Design Principles of Active Disassembly using Smart Materials (ADSM)'. The project is now funded by the EU under their 'Fifth Framework' program.

\section{Descriptions}

Before the experiments, first and second generation SMA actuators were designed with configuration prior- and post-SME described below. Force requirements over a distance under trigger temperatures were considered to force candidate product assemblies apart.

\subsection{NiTi preparation/training}

Initial experiments used NiTi ribbon actuators for releasing socketed ICs, PCBs and subassemblies ([5]). Further experiments concerned the disassembly of product housings where the metal assembly screws were removed to permit the required forces to approximate those provided by the actuators (see Table 3). Many NiTi SMA devices were superelastic in typical ambient temperatures whilst in their 100\% Martensite state, therefore annealing was necessary also removing stresses experienced since manufacturing. NiTi SMA actuators annealing and training ( [6]) are described in Table 1. These SMAs were one-way ([7]) Shape memory effect (SME) but can be mechanically deformed whilst below Martensite finishing temperature $\left(M_{f}\right)$, after their first and subsequent actuation (Fig. 1). 
Table 1. Training NiTi actuators

\begin{tabular}{|c|c|c|c|c|c|}
\hline Conditioning: & $\begin{array}{l}\text { Defomition/ } \\
\text { positioning }\end{array}$ & $\begin{array}{l}\text { Temp. } \\
\left({ }^{\circ} \mathrm{C}\right)\end{array}$ & $\begin{array}{l}\text { Time } \\
\text { (min) }\end{array}$ & $\begin{array}{l}\text { Actuation } \\
\text { force (N) }\end{array}$ & $\begin{array}{l}\text { Shape } \\
\text { recovery } \\
\text { from } \\
\text { original }\end{array}$ \\
\hline \multirow[t]{2}{*}{ Amealing: } & $=$ & 700 & 45 & $=$ & $=$ \\
\hline & Water bath & 20 & 1 & - & - \\
\hline \multicolumn{6}{|l|}{ Preparations: } \\
\hline Training & Device in jig & $420-450$ & 45 & - & - \\
\hline Quenching* & Water bath & 20 & 1 & - & - \\
\hline Defomation & Mamually to flat & 20 & - & $*$ & - \\
\hline SME & $=$ & - & $<0.5 \mathrm{~s}$ & 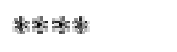 & $2 / 3-4 / 5$ \\
\hline$T_{x}: A_{g f f}$ & In produet & क⿻ & - & - & - \\
\hline $\begin{array}{l}\text { Cooling } \\
\text { cycles }\end{array}$ & Water bath & 20 & 1 & - & - \\
\hline
\end{tabular}

SMA=shape memory alloy. $T_{x}=$ transformation temperature. $-=$ not appl. SME=shape memory effect. $A_{s-f}=$ Austenite starting to finishing temperature. *Imposing $100 \%$ martensite structure (surpassing $M_{f}$ ) from $100 \%$ Austenite structure. ${ }^{* *}=$ Dependant on cross-section, composition and shape of SMA. $* * *=$ The SME $T_{x}$ depends on the SMA composition (typically between -190 to $+190{ }^{\circ} \mathrm{C}$ ); see Table $2 . * * * *=$ Force provided by the SME of the sample during dimensional change is approximately equal to the force required to mechanically deform the device plus approximately $10 \%$ for heat. $* * * * *=$ Cyclical value is highly dependent on mechanical deformation, SME, $A_{s-f}$ exposure time, SMA composition, cross-section and shape.

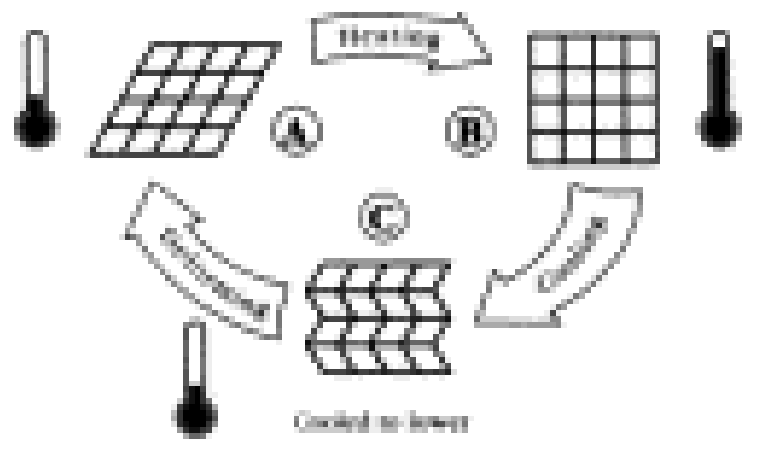

Fig. 1. The SME principle in SMA. 


\subsection{CuZnAl preparation}

The $\mathrm{CuZnAl} \mathrm{SMA} \mathrm{actuators} \mathrm{did} \mathrm{not} \mathrm{require} \mathrm{training} \mathrm{as} \mathrm{these} \mathrm{were} \mathrm{pre-trained.} \mathrm{These} \mathrm{were} \mathrm{of}$ helical design exhibiting a two-way effect ([]]). Therefore, no mechanical deformation after first and subsequent actuations was required. Some modifications were made to the devices to accommodate the experiments, see Fig. 4.

Deformation occurred in the small actuator, Fig. 2. This 'stressed' device's expanded shape was due to excessive exposure above $A_{f}$. Cycle values are severely reduced once these SMA devices are over exposed for extended periods of time. Design considerations would have to be taken into account for such applications of embedding SMA devices into consumer products.

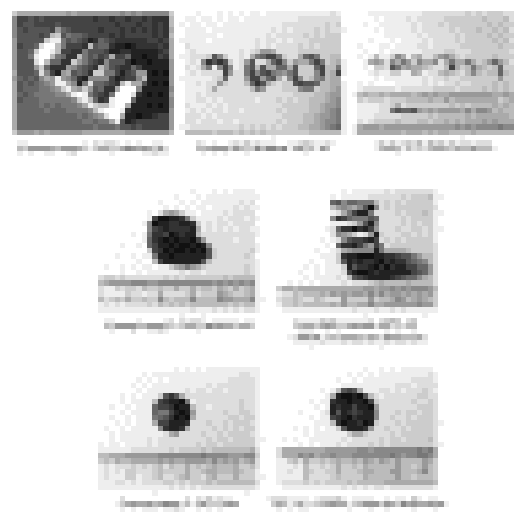

Fig. 2. Preliminary NiTi actuators.

\subsection{General SMA considerations}

SMA actuators would be in the Martensite state whilst in a product in storage/use at a typical ambient temperature range of -50 to $+90{ }^{\circ} \mathrm{C}$. As all SMA actuators are now trained, they are ready for repeated SMEs, only possible at or above their alloy-specific $A_{f}$ temperatures, Table 2 . Before incorporation into products, the actuators were cycle tested through SME trials successfully. In the first series of experiments, actuators were incorporated into product housings and heated to exceed their $A_{f}$ temperatures. The SME is time independent but takes noticeable time in the ADSM procedure as heat must be conducted through the product housing and entire actuator to undergo SME. The temperature range required for a complete SME is termed as 'Austenite start to finish' $\left(A_{s-f}\right)$. This temperature range is different than the temperature range required to induce a stable low temperature state or $100 \%$ Martensite state. The range at which this takes effect is known as Martensite start to finish $\left(M_{s-f}\right)$. These actuators returned close to their trained shapes as 
dimensional changes were approximately two thirds to four fifths of their original shapes, $\underline{\text { Table } 1}$. This is subject to their trained shapes and cross-section. Fig. 2 and Fig. 3 depict the SME travel of the actuator from flat as was observed. The actuators can be subjected to repeated deformations and SME cycles.

Table 2. SMA actuator descriptions

\begin{tabular}{|c|c|c|c|c|c|c|c|c|c|c|c|c|}
\hline $\begin{array}{l}\text { Actuator } \\
\text { typel } \\
\text { composition }\end{array}$ & Asf (") & & $\begin{array}{l}\text { PIe } \\
\text { SME } \\
\text { height }\end{array}$ & $\begin{array}{l}\text { Post } \\
\text { SME } \\
\text { height }\end{array}$ & $\begin{array}{l}\text { Force } \\
\text { (N) }\end{array}$ & $\begin{array}{l}\text { Moment- } \\
\text { deflection } \\
\text { (NM/mm) }\end{array}$ & $\begin{array}{l}\text { Required } \\
\text { ambient } \\
\left({ }^{\circ} \mathrm{C}\right)\end{array}$ & $\begin{array}{l}\text { Mass } \\
\text { aciuators } \\
\text { (g) }\end{array}$ & $\begin{array}{l}\text { O.D. } \\
\text { pre- } \\
\text { SME }\end{array}$ & $\begin{array}{l}\text { I.D. } \\
\text { peE- } \\
\text { SME }\end{array}$ & $\begin{array}{l}\text { O.D. } \\
\text { post- } \\
\text { SME }\end{array}$ & $\begin{array}{l}\text { I.D. } \\
\text { post- } \\
\text { SME }\end{array}$ \\
\hline Dise Nili & 60 & 70 & 3.0 & 1.2 & 3200 & 1.80 & 70 & 096 & 13.0 & & & \\
\hline Rod NiII-1 & 52 & 60 & 2.3 & 6.0 & 63.7 & 0.838 & 60 & 0.71 & 2.2 & & & \\
\hline Rod NTI-? & 52 & 60 & 2.3 & 6.0 & 63.7 & 0.828 & 60 & 057 & 2.2 & & & \\
\hline \multicolumn{13}{|l|}{ Coil NiT: } \\
\hline Med-1 & 45 & 60 & 14.0 & 30,0 & $>500$ & 16,0 & 60 & 4.93 & 17.8 & 140 & 18.0 & 14,0 \\
\hline Med_-2 & 45 & $60-96$ & 39.2 & 42,0 & $>500$ & 12.8 & 100 & 5.35 & 17.2 & 13 & 21 & 15.4 \\
\hline Large-1 & 95 & 100 & 31.0 & 44.8 & $>500$ & 13.8 & 120 & 902 & 19.7 & 14 & 23 & 19.7 \\
\hline Large-2 & 95 & 100 & 23.5 & $7 \geq 0$ & $>500$ & 48.5 & 130 & 617 & 180 & 130 & 19 & 13.5 \\
\hline \multicolumn{13}{|l|}{ Coil CoZnAl: } \\
\hline Sml coat & $62-77$ & $72-87$ & 6 & $11-14$ & $3-6,3$ & $5-8$ & 85 & $\sim 1.5$ & 10.1 & 7.5 & 10 & 7.5 \\
\hline Snl. Xeont & $63-68$ & $68-77$ & 6 & $12-13$ & $3-6.3$ & $6-7$ & 85 & $\sim 15$ & 10.1 & 75 & 10 & 7.5 \\
\hline Med, cort & $62-72$ & $70-77$ & 11 & $18-22$ & $12-13,5$ & $7-11$ & 85 & $\sim 3.0$ & 11.2 & 7.7 & 11 & 7.5 \\
\hline Med Xcoat & $73-75$ & $85-90$ & 10 & $17=19$ & $12-13,5$ & $7=9$ & 100 & $\approx 28$ & 100 & 75 & 10.0 & 7.5 \\
\hline
\end{tabular}

$-=$ not applicable, all dim. $( \pm 0.1)$ in $(\mathrm{mm})$ unless stated, and degrees $\left({ }^{\circ} \mathrm{C}\right)=$ Celsius .

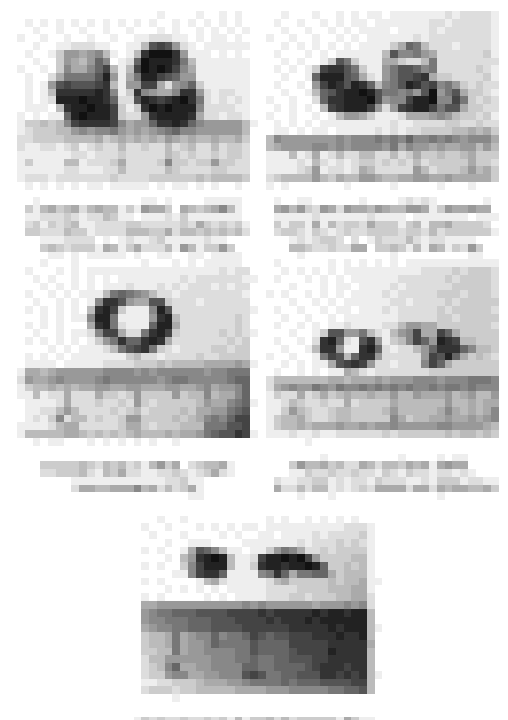

Fig. 3. Preliminary $\mathrm{CuZnAl}$ actuators. 


\section{Results}

\subsection{Experiment set 1}

All sub assembly experiments were unsuccessful regardless of actuators used, Table 3 . This was due to their designs and the complexity of the PCB/IC assemblies. The remainder of the experiments proved successful for all but one. Both NiTi and $\mathrm{CuZnAl}$ actuators were successful as the force provided by the actuators exceeded the tensile forces of the snap fasteners holding the housing assemblies together. As initial experiments proved successful, further work was attempted on testing these and other products in a controlled hierarchical temperature regime.

Table 3. Results: experiment set 1

\begin{tabular}{|c|c|c|c|c|c|c|c|c|}
\hline & \multirow{2}{*}{$\begin{array}{l}\text { Drop } \\
\text { tests }\end{array}$} & \multicolumn{4}{|c|}{ Total forces provided by actuators } & \multirow{2}{*}{$\begin{array}{l}\text { Separation } \\
\text { forces } \\
\text { required* }\end{array}$} & \multirow{2}{*}{$\begin{array}{l}\text { No. of } \\
\text { snap } \\
\text { fits }\end{array}$} & \multirow{2}{*}{$\begin{array}{l}\text { Trial } \\
\text { result }\end{array}$} \\
\hline & & $\begin{array}{l}\text { NiTi-1 } \\
\text { ribbons }\end{array}$ & $\begin{array}{l}\text { NiTi-2 } \\
\text { rods }\end{array}$ & $\begin{array}{l}\mathrm{Cu} \mathrm{ZnAl}_{\mathrm{nAl}} \\
\mathrm{h} \text {, coils } 1\end{array}$ & $\begin{array}{l}\mathrm{Cu} / \mathrm{nAl} \\
\mathrm{h}, \text { coils } 2\end{array}$ & & & \\
\hline \multicolumn{9}{|c|}{ Sub assembly trials: } \\
\hline $\mathrm{IC} 1$ & - & $<F$ & - & - & - & $X$ & - & Failure \\
\hline IC 2 & - & $<F$ & - & - & - & $\mathrm{X}$ & - & Failure \\
\hline PCB 1 & OK & $<F$ & - & - & - & $\mathbf{X}$ & - & Failure \\
\hline TI & OK & $<F$ & $124-128$ & $\angle F$ & $<F$ & $\mathrm{X}$ & - & Failure \\
\hline
\end{tabular}

\begin{tabular}{|c|c|c|c|c|c|c|c|c|}
\hline \multicolumn{9}{|c|}{ Small electronic product housing rials: } \\
\hline Royal DM75 & $\mathrm{OK}$ & - & $124-128$ & No trial & No trial & $\mathrm{XXX}$ & 11 & Success \\
\hline Camon calcltr & $\mathrm{OK}$ & $=$ & $124-128$ & No trial & No trial & 30 & 6 & Success \\
\hline Canon calclin? & $\mathrm{OK}$ & - & $>F$ & $48-54$ & n.a. & 30 & 6 & Success \\
\hline Brats 1 & OK & - & $>F$ & $48-54$ & $n_{i} a_{n}$ & 12 & 6 & Success \\
\hline Sharp calc. & $\mathrm{OK}$ & - & $>F$ & $48-54$ & n.a. & 64 & 6 & Success \\
\hline Brats ? & $\mathbf{x}$ & - & $>F$ & $n, a$. & 24 & 26 & 6 & Failuxe ${ }^{+}$ \\
\hline
\end{tabular}

Total force components

$(62-64) \times 2 \quad(12-13.5) \times 4 \quad(6 \times 2)+4+8$

-=not applicable; $\mathrm{X}=$ not tested; $\mathrm{XXX}=$ altered in earlier trials; $<F=$ insufficient force, cross-sections were likely too low for these product assemblies; $>F=$ excessive force for this particular application, **ADSM force required (20 tensometer each); ${ }^{+}$successful disassembly, but inspection revealed excessive wear on snap fits.

\subsection{Experiment set 2}

Earlier experiments tested ADSM with limited control. Set 2 addresses this. With SMA actuators inside the candidate products, they entered a sequence of controlled temperature changes where the SMA devices activated at appropriate stages, Table 4. Here, ADSM occurs allowing components to be non-destructively dismantled. 
Table 4. Hierarchical temperature regime of actuator employment by stage for experiment set 2

\begin{tabular}{|c|c|c|c|c|}
\hline $\begin{array}{l}\text { Actuator } \\
\text { composition: }\end{array}$ & $\begin{array}{l}\text { Actual } \\
\text { actuator } \\
\text { SME } A f \\
\text { (C) }\end{array}$ & NiTi & $\begin{array}{l}\text { Nili and } \\
\text { CuZnAl }\end{array}$ & NiTi \\
\hline $\begin{array}{l}\text { Actuator design: } \\
\text { Stages in ambient } \\
\left.\text { heat provided ( }{ }^{\circ} \mathrm{C}\right) \text { : }\end{array}$ & & Rods & $\begin{array}{l}\text { Helical } \\
\text { coils }\end{array}$ & Discs \\
\hline $1=70^{2}$ & 60 & $x$ & $X$ & $X$ \\
\hline $2-85$ & $68-80$ & & $\mathrm{X}$ & \\
\hline $3=100$ & $80-90$ & & $X$ & \\
\hline $4=120$ & 100 & & $x$ & \\
\hline
\end{tabular}

Before experiments, actuators were inserted in macro and subassemblies of test products. Prior trials tested for appropriate placement, combinations of actuators in place and hierarchy of anticipated ADSM outcomes. This consisted of placing lower $A_{f}$ SMA actuators in the macro assemblies and higher $A_{f}$ actuators in the subassemblies, Fig. 4.

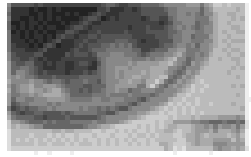

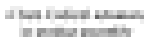
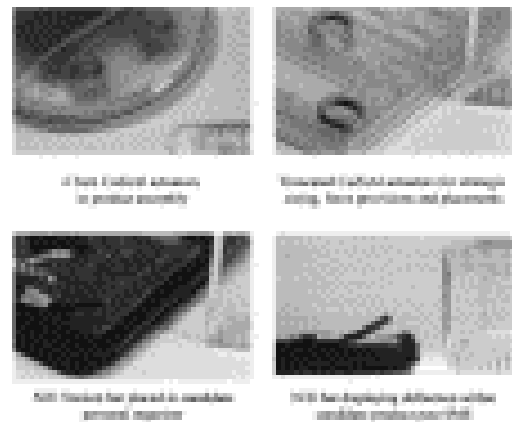

Fig. 4. NiTi and $\mathrm{CuZnAl}$ actuators placed inside candidate products.

The entire sample base was then placed in a hot air chamber. The temperature was then raised from 20 to $75^{\circ} \mathrm{C}$ (stage 1) with results reported. The hierarchy in temperature regime continued from 70 to $115^{\circ} \mathrm{C}$ for stages 2,3 and 4 , Table 4 . These temperatures were chosen to surpass the $A_{f}$ of actuators by at least $5{ }^{\circ} \mathrm{C}$.

General actuator placements for the corresponding hierarchical disassembly experiments are characterised for the candidate products, Table 5. $A_{f}$ temperatures of actuators, design types (including same product category comparisons) and particular product assembly separation force 
required pertinent to the disassembly, etc., are noted in Table 5. These conditions will be used in the investigation of design guidelines of the generic application of ADSM using SMA employed in these experiments in future work. Disassembly hierarchies range from a one product/one time selfdisassembly with one actuator inside to a 3-time self-disassembly within one product housing four actuators. Table 2 has actuator descriptions of those employed in the experiments.

Table 5. Results, experiment set 2

\begin{tabular}{|c|c|c|c|c|c|c|c|c|}
\hline \multirow[t]{2}{*}{$\begin{array}{l}\text { Candidate } \\
\text { products }\end{array}$} & \multicolumn{3}{|c|}{$\begin{array}{l}\text { Heranchical actuator placement } \\
\text { by product }\end{array}$} & \multirow{2}{*}{$\begin{array}{l}\text { Hierarchy } \\
\text { within } \\
\text { product? }\end{array}$} & \multirow[t]{2}{*}{$\begin{array}{l}\text { ADSM } \\
\text { technique }\end{array}$} & \multirow{2}{*}{$\begin{array}{l}\text { Results } \\
\text { slages } \\
\text { of } \\
\text { ADSM }\end{array}$} & \multirow{2}{*}{$\begin{array}{l}\text { Fully } \\
\text { suceessful } \\
\text { ADSM? }\end{array}$} & \multirow{2}{*}{$\begin{array}{l}\text { Instant } \\
\text { ADSM? } \\
\text { ( } 53 \text { s) }\end{array}$} \\
\hline & Placement & $\begin{array}{l}A_{f}(C) \text { at } \\
\text { ADSM }\end{array}$ & $\begin{array}{l}\text { Actuator } \\
\text { type }\end{array}$ & & & & & \\
\hline $17^{m}$ & \multicolumn{3}{|c|}{$\begin{array}{l}\text { Affempted at glass seam, } \\
\text { further development required }\end{array}$} & & Friled & $=$ & $=$ & $=$ \\
\hline PC keyboard & \multicolumn{3}{|c|}{ Attempted on macro assembly } & - & Failed & - & - & - \\
\hline Mot, mobile-1 & Botfom end & 60 & Rod NiTI & No & Snap fit expansion & 1 & No & No \\
\hline Mol. mobile-? & Mididle & 60 & Rod NiTi & No & & 1 & No & No \\
\hline Mot, mebile-3 & \multicolumn{3}{|c|}{ Aftempts on macro assembly } & - & Failed & - & - & - \\
\hline Mot, mobile-4 & \multicolumn{3}{|c|}{ Aftempts on sub assembly } & - & Failed & - & - & - \\
\hline \multirow[t]{2}{*}{ PC mouse } & Center rear & 60 & Helical coil NiTi & \multirow{2}{*}{$\frac{2}{p}$ stage } & \multirow{2}{*}{ Snap fit expansion } & 1 & Yes & No \\
\hline & Keys front & 73,73 & Helical coil GuZnAl & & & 2 & Yes & No \\
\hline \multirow[t]{2}{*}{ Shapp Galctr } & Topend & 60 & Helical coil NiTi & \multirow{2}{*}{$\frac{2}{y}$ stage } & \multirow{2}{*}{ Snap fit expansion } & 1 & Yes & Yes \\
\hline & Middle & 85,85 & Helical coil CuZnAl & & & 2 & Yes & Yes. \\
\hline Apple Adj. $\mathrm{K}^{\mathrm{d}}$ & Front and & 70 & Disc NiTi & No & \multirow{2}{*}{ Snap fit expansion } & 1 & No & $\mathrm{No}$ \\
\hline \multirow[t]{2}{*}{ Batt, eharger } & \multirow[t]{2}{*}{ Bottom end } & 68,70 & Helical coil GuZnAl & \multirow{2}{*}{$\frac{2}{n}$ stage } & & 2 & No & No \\
\hline & & 100 & Helical coil NiTi & & Conpression fit expansion & 4 & No & No \\
\hline Kodak S, U. & Top middle & 70 & Helical coil CulnAl & 2 stage & Snap fit expunsion & 2 & Yes & No \\
\hline Camera-1 & Side & 70 & Helical coil GuZnAl & & & 2 & Yes & No \\
\hline Kodak S,U. & Center bottom & 70 & Helical coil CuZnAl & \multirow{3}{*}{$\begin{array}{l}3 \text { stage } \\
\text { it }\end{array}$} & \multirow{3}{*}{ Snap fit expansion } & 2 & Yes & No \\
\hline \multirow[t]{2}{*}{ Camera-2 } & Top right & 72,72 & Helical coil CuZnAl & & & $2 / 2$ & Yes & No \\
\hline & Top middle & 73 & Helical coil CuZnAl & & & 2 & Yes & No \\
\hline Sung PC & Key seats & 71,72 & Helical coil CuZnAl & 2 stage & Snap fit expansion & 2 & Yes & No \\
\hline Mouse-1 & PCB bottom & 85,85 & Helical coil CuZnAl & ${ }^{t}$ & Compression fit expansion & 3 & Yes & Ne \\
\hline Brats Cale ' $O$ ' & End & 75,77 & Helical coil CuZnAl & No & Snap fit expansion & 2 & Yes & No \\
\hline Royal P.O. & Center & 77,77 & Helical coll GuZnAl & No & Snap fit expansion & 2 & Yes & Yes. \\
\hline T1 Calculator & End & 76,75 & Helical coil CvZnAl & No & Snap fit expansion & 2 & Yes & Yes. \\
\hline Brats Calc. Sq & Middle & 80 & Helical coil CuZnAl & No & Snap fit expansion & 2 & Yes & No \\
\hline Canon Calchr & Ends diag. & 80,80 & Helteal coll CuZnAl & No & Snap fit expansion & 2 & Yes & Yes \\
\hline Eleme Game & Middle & 90,90 & Helical coil CuZnAl & No & Conpression fit expansion & 3 & Yes & Yes \\
\hline Adj. tKypd & Center rem & 100 & Helical coil NiTi & No & Snap fit expansion & 4 & No & No \\
\hline
\end{tabular}

$-=$ not applicable, degrees $(C)=$ Celsius .

Most candidate products proved successful in the temperature/hierarchical generic ADSM experiments. Only the A4 (17") CRT, one PC keyboard and two of the four mobiles were not fit for the disassembly experiments as placement of the actuators proved unpractical. Of the 55 actuators employed, SME was successful with some of the two-way $\mathrm{CuZnAl}$ actuators over stressed and thus not able to provide SME to the designed specifications repeatedly, Fig. 2. Of the 21 products, four were unable to be tested. Of the remaining 17, 12 products successfully dismantled with 19 SME disassembly occurrences since some of the products were of a multistage nature. Of the five products unsuccessful, six failures occurred in total. The failed experiments made it clear that exposure to ambient temperature was insufficient. As SME is 
temperature-dependent, it is crucial that allowances be made in the product sub- and macro assemblies for ambient temperatures to affect the SMA devices before destroying the product.

Of all the products tested, seven were multi-stage and one, the Kodak S.U. Camera-2, was a 3stage all within the temperature regime 'Stage of Disassembly 2'. The SMA devices in this application successfully dismantled the camera at 70,72 and $73{ }^{\circ} \mathrm{C}$. This camera's result exhibits some accuracy potential within an active or self-disassembly system as a generic process. Table 5 describes the nature of experiments throughout the four stages of the hierarchical disassembly/temperature regimes.

\subsection{Impact on product design}

After experiments were conducted, examinations were made for necessary design modifications that would be required to manufacture products with SMA devices for use in the ADSM dismantling process (Fig. 5) [9]. Besides accepted design for end-of-life, improved incorporation of ADSM would include:

'Smart Material Devices' (SMDs) proximity by hierarchy and clean separation at $A_{f}$.

Vectorial passage for ambient temperature increase is necessary to induce $A_{f}$.

Location-specific force provision surpassing tensile force of product enclosure.

Controlled trigger temperature and time balance effects on product relative to disassembly procedure with tight tolerances for SMD and product enclosures.

SMD design depends on product applications for best results; standardisation can be achieved for applications requiring specific execution.

Typically, SMDs would be below $M_{f}$ at typical ambient temperatures $\left(-50\right.$ to $\left.+90{ }^{\circ} \mathrm{C}\right)$.

Trigger temperatures must be specified for a timely active disassembly.

Controlled break points, over-specification reduction, simplification, hierarchy of subassemblies and vinculum strength reduction improve the ADSM procedure.

The use of a non-specific disassembly line would optimise the potential of ADSM. 


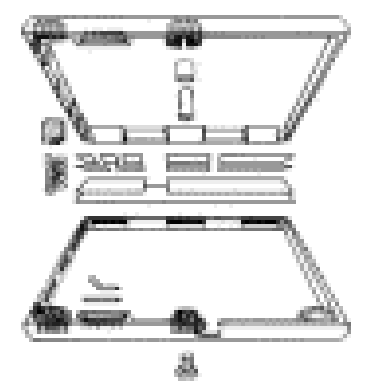

Fig. 5. Typical changes to product design accommodating shape memory devices.

Although ADSM could be implemented without any added costs using Shape Memory Polymer (SMP), very minor initial cost increases would be evident in SMA inclusion applications. New product design must include some changes to the housing of candidate products if ADSM were to take place if the near minimum energy is to be consumed in the ADSM process. One of the greatest advantages of ADSM is the versatility in cost, design changes and potential industrial implementations. Further work currently under way, demonstrates the principles of these parameters.

\section{Conclusions}

Product design must include some changes to the housing of the intended products if active or selfdisassembly were to take place otherwise, significant damage can result potentially eliminating one of the benefits of the ADSM process. Earlier work has found similar requirements in design changes necessary for self-disassembling [10]. Other observations suggest SMA devices should not be exposed to significantly higher temperatures than their $A_{f}$ for an extended period of time as this affects cyclical values, Fig. 3. Future work will address these and other issues. Most of the products disassembled in this study proved successful, Fig. 4.

Other smart materials have also been employed for the ADSM process. Shape Memory Polymers (SMP) have been used in the design of releasable fasteners [11 and 12]. Both SMA and SMP were characterised from a financial feasibility perspective [13].

It seems that the feasibility of ADSM as a disassembly procedure is not completely understood or fully useful without the study of its use in a product non-specific disassembly facility. It is in this 
application that the numerous benefits of cost and feasibility in a highly individual multi-product market could be realised. As 'Take back' legislation becomes closer to reality, industrial interest increases and recyclers expand their scope of recyclable products, and within this scope, ADSM has good long-term potential.

\subsection{Environmental benefit}

The overall research is part of on-going step change studies attempting to tackle environmental impact reduction in consumer electronics in part through diversified needs scenarios [14].

Waste from electrical and electronic equipment (WEEE) is approximately $1 \%$ of total landfill yet is responsible for approximately $50-80 \%$ of the heavy metals in leachate. Few figures exist on the environmental benefit of recycling WEEE. One study, the 1997 ECTEL report observes the environmental benefit of mobile phone recycling. It shows that $2.9 \mathrm{MJ}$ is the energy credit after the mobile phones in that study were 'taken back'. This included energy required to collect and process granulation of total average product (1995-1996) with precious metals retrieved. However, if you disassemble the product using manual disassembly with component recovery (including high economic value ICs) and plastic recycling, then the ECTEL report suggests that the energy credit for similar mobile phones would be in the order of $40 \mathrm{MJ}$ per mobile. This demonstrates that one of the key environmental burdens is in the components and therefore their recovery could be very beneficial in environmental impact reduction.

Even though there is significant environmental benefit associated with component recovery, factors including cost of disassembly and reliability of the ICs currently limit the practical application of their recovery for EoL mobile phones. For future considerations, see page 39 of the ECTEL report. Whether ADSM is applicable or not to total component recovery, it would provide an economical means of dismantling the product anyway. It could be that SMA or SMP devices would provide a potential dismantling scenario for the removal of all components if one were to be developed for surface mount components.

Baring in mind the findings of SMA and SMP devices, the economic and environmental opportunities could be considerable. To date, it is the only industry wide scenario addressing the issue of non-destructive constituent component disassembly. Additionally, past work has shown that ADSM has also provided dismantling for different product layers and subassemblies in a variable temperature regime. The work continues to test applicable smart material technology. 


\section{References}

1. Chiodo JD, Billett EH. Active disassembly using SMART materials, unconventional ideas EPSRC research grant, Brunel University, Runnymede, Surrey, UK, 1996-1997.

2. Chiodo JD, Boks C. A feasibility study on active disassembly using smart materials-a comparison with conventional end-of-life strategies. Proceedings, Life Cycle Engineering. Kingston (Ontario, Canada): in press.

3. Boks C, Tempelman E. Future disassembly and recycling technology for the electronics and automotive industry. Delphi study report-K370. The Netherlands: Delft University of Technology, April 1997, pp. 10.

4. Gilbertson RG. Muscle wires project book. San Anselmo, CA., 1994:2-7.

5. Chiodo JD, Anson A, Billett E, Perkins M, Harrison D. Eco-design for active disassembly using smart materials. Proceedings, Shape Memory and Superelastic Technologies. Asilomar Conference Center (Pacific Grove, CA., USA): 1997.

6. Hodgson DE, Wu MH, Biermann RJ. Shape memory alloys. SMA Inc. (http://www. smainc.com/SMAPaper.html), 1997.

7. P. Tautzenberger In: P. Tautzenberger, D Stockel and C.M. Wayman, Editors, Engineering aspects of shape memory alloys, Butterworth-Heinemann, New York (1990) pp. 208 .

8. R.F. Gordon In: T.W. Duerig, K.N. Melton, D. Stockel and C.M. Wayman, Editors, Engineering aspects of shape memory alloys, Butterworth-Heinemann, New York (1990) pp. 245 .

9. Chiodo JD, Billett E. Preliminary outline guidelines for active disassembly. Proceedings, Product Design Education. Runnymede (Surrey, UK): Brunel University, 1997.

10. Chiodo JD, Billett EH, Harrison DJ. Active disassembly. J Sustain. Des. (7) ISSN 1367-6679. 11. Chiodo JD, Billett EH, Harrison DJ. Preliminary investigations of active disassembly using shape memory polymers. Proceedings of the First International Symposium on Environmentally Conscious Design and Inverse Manufacturing. Tokyo (Japan): IEEE, 1999:590-596. ISBN 07695-0007-2.

12. Chiodo JD, Billett EH, Harrison DJ. Active disassembly using shape memory polymers for the mobile industry. IEEE International Symposium on Electronics and the Environment. Danvers (MA, USA): ISEE, 1999:559-596. ISBN 0-7695-0007-2.

13. Chiodo JD, Boks C. Assessment of end-of-life strategies with active disassembly using smart materials. Journal of Sustainable Design. In Press. 
14. Chiodo JD, Simpson PJ, Billett EH. Socially responsible design eco-needs scenario comparison. Proceedings, Product Design Education. Runnymede (Surrey, UK): Brunel University, 1997. 